\title{
Older Homeless Adults: Can We Do More?
}

\author{
Margot Kushel, MD
}

Division of General Internal Medicine, University of California San Francisco, San Francisco General Hospital, San Francisco, CA, USA.

$\mathrm{J}$ Gen Intern Med 27(1):5-6

DOI: $10.1007 / \mathrm{s} 11606-011-1925-0$

(c) Society of General Internal Medicine 2011

$\mathrm{T}$ he average age of individuals experiencing homelessness is rising. Between the early 1990 s and 2003 , the proportion of homeless adults aged 50 and older increased from $11 \%$ to nearly one-third ${ }^{1}$. This trend continues. Demographic research has shown that for the last 20 years, adults born in the second half of the "baby boom" (mid-1950s to 1964) have experienced a sustained elevation in their risk of experiencing homelessness ${ }^{2}$. As this population ages, so does the average age of the homeless population. Prior research completed when the homeless population was younger showed that adults experiencing homelessness have higher rates of physical health, mental health and substance use problems than housed individuals ${ }^{3,4}$. Homelessness is associated with poor access to health care and high rates of Emergency Department visits and inpatient hospitalizations, and high rates of early mortality ${ }^{4-7}$. Prior research has shown excess mortality within all age groups within the homeless populations, but differences in causes of death by age group. The elevated mortality among younger homeless adults is caused by trauma, infectious diseases and complications of substance use $^{7}$. In contrast, mortality among older homeless adults is caused by heart disease and cancer ${ }^{5,8}$. Thus, the aging of the homeless population raises important clinical questions about health priorities among this population.

In this issue of JGIM, Brown et al. examined some of the clinical implications of this demographic shift ${ }^{9}$. The authors systematically recruited English-speaking homeless adults ages 50 to 70 from homeless shelters in Boston for a crosssectional study, in order to examine rates of geriatric and chronic health conditions. They found high rates of geriatric and chronic health conditions, mental health and substance use disorders. Over half of the participants had fallen in the past year; 30\% reported difficulty with performing at least one activity of daily living (ADL) and 57\% reported difficulty with at least one instrumental activity of daily living (IADL), common markers of risk for hospitalization, nursing home placement and mortality ${ }^{10,11}$. A quarter had evidence of cognitive impairment or deficits in executive function. Almost one-third reported difficulty hearing, and half reported urinary incontinence. These rates far surpass those of nonhomeless older adults 20 years older than the homeless adults. Self-rated health and chronic conditions were also high. Furthermore, Brown's research shows very high rates of

Published online November 16, 2011 depression, with rates double and triple those found in other community-based cohorts of much older adults. Depression in older adults is associated with worsened cognitive function, decreased ability to manage chronic conditions and higher likelihood of nursing facility placement ${ }^{12}$. While the rates of alcohol and drug problems found among older homeless adults were lower than younger homeless adults, they were much higher than comparison cohorts. Higher rates of prior substance use may have contributed to the development of the geriatric conditions and chronic diseases; they will also complicate management.

This research shows a highly vulnerable population living with high rates of disability. Brown et al. assert that "geriatric syndromes are preventable or amenable to relatively simple interventions." While this is true in the general population, some of the interventions that have shown benefit may be difficult, if not impossible to implement among homeless individuals. Many of the impairments that they found may be attributed in part to limited access to health care coupled with high rates of harmful health behaviors and unintentional injuries. But disability is more complicated than a collection of impairments; it is a result of a complicated interaction between a level of impairment and environment. A primary strategy to reduce disability is to make environmental modifications ${ }^{13}$. Homelessness is an extreme example of the inability to control or alter one's environment. Adults living on the street or in homeless shelters are unable to modify their "home environment" to prevent falls; extremely limited access to toileting facilities complicates efforts to manage incontinence. Corrective lenses and hearing aids for sensory impairments may be out of economic reach for homeless individuals, or easily lost or damaged in the chaos of street and shelter life. So, while certain recommendations are in health care providers' control (reducing polypharmacy, avoiding medications with cognitive side effects and ordering physical therapy evaluations), these alone are likely inadequate. When faced with a relatively large group of older adults experiencing homelessness, we need to look for solutions that go beyond simple interventions.

There are many pathways into and out of homelessness. The most important way to prevent the specter of older adults living with significant disability on the streets is to prevent homelessness from happening. This would require a better understanding of the different pathways to homelessness and a concerted effort to interrupt these. Research has shown that when individuals lose their housing at older ages or have more co-morbid conditions, they are more likely to become chronically homeless. The participants in Brown's study had a mean age of first homelessness at 43, and two-thirds had been homeless for more than 1 year, the most common definition of chronic homelessness. A decade ago, research 
on the high rates of Emergency Department and inpatient hospitalization and a growing realization of the enduring nature and human cost of chronic homelessness helped motivate the creation, funding and expansion of supportive housing ${ }^{14,15}$. Supportive housing, or subsidized housing linked with on-site or closely linked supportive services (medical, psychiatric, vocational, social work, substance abuse treatment), has been shown to maintain housing, improve health outcomes and reduce acute health utilization for chronically homeless individuals ${ }^{15}$. Recent decreases in rates of chronic homelessness, despite increases in rates of homelessness overall, have been attributed to the dramatic expansion of supportive housing in many parts of the US ${ }^{16}$. While relatively costly, research has suggested that for selected populations of high-risk individuals such as those at high risk for extended stays in psychiatric facilities, supportive housing costs are neutralized by savings in institutional costs ${ }^{14}$. Supportive housing has been shown to decrease re-hospitalization among people with HIV and other chronic illnesses who are discharged from the hospital ${ }^{17,18}$. Supportive housing's many successes have led to growing support from many governmental agencies; there is interest in funding some of the services via Medicaid. But demand still outstrips supply. Could supportive housing be expanded to meet the needs of older adults experiencing homelessness? It is not known whether supportive housing could effectively decrease institutional care in this population, but success within other populations with multiple chronic health conditions is suggestive that it might. Little is known about the trajectory of homelessness among frail older adults, but Brown's demonstration of high rates of conditions associated with the need for institutional care suggests that many may require early nursing home placement.

In the general community, we devote effort to keeping people out of long-term care facilities and in the community, both because we believe that individual self-determination is important and because community care is less costly. Programs such as Program of All Inclusive Care for the Elder (PACE) that provide wraparound care for older adults living in the community have demonstrated success in avoiding acute medical care. ${ }^{10}$ The Medicaid Home and Community Based Services (HCBS) program pays for home-based services for individuals who otherwise would be reliant on institutional care; the proportion of Medicaid spending for long-term care that supports HCBS has increased in the past decade. In Brown's study, the vast majority of participants were insured by Medicaid. While this is not the case among homeless individuals nationwide, it will be once health reform is enacted. The average annual cost of a skilled nursing facility is $\$ 50,000-60,000$. If a large proportion of older homeless individuals receive institutional care that could have been prevented, we may find the political will to consider policies that could prevent or ameliorate homelessness. If supportive housing could safely keep chronically homeless frail older adults out of institutional care, it may be both cost-effective and humane.

Widespread homelessness has persisted for 3 decades, but the face of it has changed. With the specter of large numbers of frail, older people living on our streets, there is a moral imperative to intervene. In light of a poor economic climate that may both place more vulnerable older individuals at risk of homelessness and threaten the safety net that cares for them, demographic projections of a continued rise in the proportion of homeless adults who are over aged 50, and compelling data describing the frailty of this population, we may have an economic incentive to do so as well. Health reform may offer a chance to address homelessness among frail elderly. If ending homelessness among older adults isn't motivation enough, then perhaps the prospect of rapidly escalating costs will provide the necessary push.

Corresponding Author: Margot Kushel, MD; Division of General Internal Medicine, University of California San Francisco, San Francisco General Hospital, UCSF Box 1364, San Francisco, CA 94143, USA (e-mail: margot.kushel@ucsf.edu).

\section{REFERENCES}

1. Hahn JA, Kushel MB, Bangsberg DR, Riley E, Moss AR. Brief report: the aging of the homeless population: fourteen-year trends in San Francisco. J Gen Intern Med. 2006;21(7):775-778.

2. Culhane DP, Metraux S, Bainbridge J. The Age Structure of Contemporary Homelessness: Risk Period or Cohort Effect? Penn School of Social Policy and Practice Working Paper 2010.

3. Brickner PW, Scanlan BC, Conanan B, et al. Homeless persons and health care. Ann Intern Med. 1986;104(3):405-409.

4. Kushel MB, Vittinghoff E, Haas JS. Factors associated with the health care utilization of homeless persons. JAMA. 2001;285(2):200-206.

5. Hwang SW, Orav EJ, O'Connell JJ, Lebow JM, Brennan TA. Causes of death in homeless adults in Boston. Ann Intern Med. 1997;126 (8):625-628.

6. Hibbs JR, Benner L, Klugman L, et al. Mortality in a cohort of homeless adults in Philadelphia. N Engl J Med. 1994;331(5):304-309.

7. Barrow SM, Herman DB, Cordova P, Struening EL. Mortality among homeless shelter residents in New York City. Am J Public Health. 1999;89(4):529-534.

8. Hwang SW, Wilkins R, Tjepkema M, O'Campo PJ, Dunn JR. Mortality among residents of shelters, rooming houses, and hotels in Canada: 11 year follow-up study. BMJ. 2009;339:b4036.

9. Brown RT, Kiely DK, Bharel M, Mitchell SL. Geriatric Syndromes in Older Homeless Adults. J Gen Intern Med. 2012; 27. doi:10.1007/ s11606-011-1848-9

10. Sands LP, Wang Y, McCabe GP, Jennings K, Eng C, Covinsky KE. Rates of acute care admissions for frail older people living with met versus unmet activity of daily living needs. J Am Geriatr Soc. 2006;54 (2):339-344.

11. Carey EC, Walter LC, Lindquist $\mathbf{K}$, Covinsky KE. Development and validation of a functional morbidity index to predict mortality in community-dwelling elders. J Gen Intern Med. 2004;19(10):1027-1033.

12. Okura T, Plassman BL, Steffens DC, Llewellyn DJ, Potter GG, Langa KM. Neuropsychiatric symptoms and the risk of institutionalization and death: the aging, demographics, and memory study. J Am Geriatr Soc. 2011;59(3):473-481.

13. Verbrugge LM, Jette AM. The disablement process. Soc Sci Med. 1994;38(1): 1-14.

14. Culhane DP, Metraux S, Hadley T. Public service reductions associated with placement of homeless persons with severe mental illness in supportive housing. Hous Policy Debate. 2002;13(1):107-163.

15. Culhane DP, Byrne T. Ending Chronic Homelessness: Cost-Effective Opportunities for Interagency Collaboration. Penn School of Social Policy and Practice Working Paper;2010.

16. US Department of Housing and Urban Development. The 2010 Annual Homeless Assessment Report to Congress, 2011.

17. Buchanan DR, Kee R, Sadowski LS, Garcia D. The Health Impact of Supportive Housing for HIV-Positive Homeless Patients: A Randomized Controlled Trial. Am J Public Health. Apr 162009.

18. Sadowski LS, Kee RA, VanderWeele TJ, Buchanan D. Effect of a housing and case management program on emergency department visits and hospitalizations among chronically ill homeless adults: a randomized trial. JAMA. 2009;301(17):1771-1778. 